\title{
Challenges and Opportunities for Assessing Cultural Landscape: an Ecomuseum for Cultural-Based Local Development
}

\author{
Giuseppina Cassalia ${ }^{1, a}$, Claudia Ventura ${ }^{1, b}$ \\ ${ }^{1}$ Mediterranea University of Reggio Calabria - PAU - Department of Heritage, Architecture, Urban \\ Planning, Via Salita Melissari - 89124, Reggio di Calabria, Italy \\ a giuseppina.cassalia@unirc.it, b claudia.ventura@unirc.it
}

Keywords: Strategic planning, Cultural Landscape, Heritage, Rural areas.

\begin{abstract}
This study arises from applied research in regional contexts combined with a deep analysis of cultural landscape potential for socio-cultural and economic local development. In addition, it starts from a careful critical reflection on traditional governance models of naturalistic contexts located on the sidelines of metropolitan suburbs in delay development. It is aimed at deepening the theoretical recognition of the identifying characteristics of the Aspromonte National Park as an inseparable reality and to the definition of "rurality" as an important tourist attraction and as endogenous development. Moreover the paper present a summary of a pilot project for the definition, assessment and implementation of a model of Ecomuseum of the Cultural Landscape, through the identification of homogeneous territorial areas in which to conduct experimentation and implementation of management models able to trigger processes of exploitation and growth of the Aspromonte area thanks to an innovative strategic planning focused on the community involvement and heritage enhancement.
\end{abstract}

\section{Introduction}

The enhancement of the cultural landscape in rural areas located at the edge of developing metropolitan cities starts from the recognition of its historical, cultural and environmental issues, up to the definition of the strengths point of the area. Protected natural areas are characterized by a mixture of places and resources often poorly valorised, which, especially in southern Italy, are often not covered by the common tourist trails, focusing on a few visits to the major city centers / attractions. The Laboratory evaluations and economic appraisals (LaborEst) of the Department PAU, Mediterranean University of Reggio Calabria, for years conducted research related to the assessment of socio-economic impacts arising from investments in the field of Cultural Heritage and Environment. It has studied the issues aimed at achieving sectorial and feasibility studies for the implementation of integrated projects aimed to the conservation of the heritage value of the historic and environmental, urban regeneration and revitalization of the inner areas of Calabria Region, supporting the implementation of policies in the field the restoration and enhancement of historic centers, the urban regeneration and revitalization of the inner areas, facilitating access to financial resources at national, regional and European Union [1].

The research conducted in the last five years, have led to the activation (through internships, based on residential and desk activities) of a laboratory course of study and research that has focused on defining the framework of the possible strategic scenarios, creating strategic guidelines for local development within the Aspromonte National Park. It has developed a careful planning to consider the potential inherent to cultural resources (tangible and intangible) and environmental of Grecanic Aspromonte. This area is a unique combination of landscapes, culture, history, traditions, and many experts consider it as the southern Italy area with the highest percentage of the identifying characteristics of Reggio Calabria province, in terms of traditions, cultures and languages. Aspromonte is the keeper of the identity of an extended part of Calabria, which also involves many aspects of the other part of the Strait of Messina territory, a witness of that culture who survived to the 
pastoral sedentarization which affected the agricultural landscape with a design free from constraints of human settlement.

The Aspromonte Grecanico is pure nature, which rather than being corrupt, corrupts those who come in contact with: community, landscapes, lifestyles, economy, often represent values with extraordinary potential because it is included in a habitat that affects every aspect of everyday life.

On such evaluations, the present study illustrates the theoretical and methodological aspects that have sparked new lines of research, orientating new strategies to enhance and to vehiculate the intangible culture embedded within paths of the economic, cultural and social enhancement. Therefore the base of these considerations has focused on the important role of place perception in the territorial preservation and enhancement dynamics of the cultural and historical heritage, especially of what is considered "minor" heritage resources. The territory is vulnerable when is not perceived in its potential size. The misreading of its vocations determines wrong or at best ineffective interventions due to the lack of shared decision making policies.

The project proposal presented in this paper is to establish a Network of Ecomuseums of the Aspromonte National Park, able to relate properly to the theme of identity and working for the emergence of anthropogenic and natural values of the area.

The reflection behind the project is focused on the convincement that for the enhancement of the Aspromonte, it is not enough to work just on heritage protection actions, but it is essential to bring out the authentic culture of the Aspromonte as the main theme of the planning actions.

Despite a precise set of single heritage element of recognized excellence, both in terms of natural and anthropogenic resources, the "cultural landscape" system makes the Aspromonte an area dense of unique and extraordinary meanings that chisel its identity under every point of view. Aspromonte is popular culture, tradition, folklore, rituals, food, and all signs of an unmistakable identity still alive in the communities that animate the centers of the Park.

Then it is necessary to work on identity heritage, starting from the assumption that the material elements of culture are always and only the tangible "shape" of immaterial culture (past or current) that determined the conformation and characteristics. Then it is required to focus on the genius loci or sense of place, the authentic identity and its perception, in order to correct the internal and external perceptual distortions that underlie the fragility of enriching programs and initiatives.

It is from this insight that break out to the proposal of the Network of Ecomuseums of Aspromonte National Park: a territorial structure open to the community, scientific research bodies, associations and local administrations, acting to study, develop and promote the cultural identity of Aspromonte especially among the younger generation and foreigners. The Network of Ecomuseums is conceived as part of the National Park, which through various partnership levels (institutional, scientific, social) is called to carry out research and documentation, knowledge transfer, but at the same time the creation of a compatible tourism offer, developing local economic activity, improving and diversifying the use of cultural heritage.

\section{Ecomuseums and Cultural Landscape Enhancement}

Cultural landscape background. Landscapes are complex phenomena. In addition to the assemblage of physical features on which geographers and others focused until the last thirty years or so, it is now widely accepted that landscapes reflect human activity and are imbued with cultural values. They combine elements of space and time, and represent political as well as social and cultural constructs. As they have evolved over time, and as human activity has changed, they have acquired many layers of meaning that can be analysed through historical, archaeological, geographical and sociological studies.

The world paradigm shifted once 2004 Declaration on Heritage Landscapes [2] was adopted at International Council on Monuments and Sites (ICOMOS) International Symposium. This declaration focuses on cultural landscapes in terms of the " interaction of people and nature over time". In face of their variety and heterogeneity, cultural landscapes are influenced by different 
institutional systems with different goals and logics of actions. Cultural landscapes cannot be developed intentionally as a whole and because of the given interrelated exchanges, back-and-forth issues can occur [3]. Cultural landscapes are more or less a by-product of sectorial policies and diverse human activities and in that sense a common good [3]. The character of the landscape thus reflects the values of the people who have shaped it, and who continue to live in it. The culture itself is the shaping force. Landscape is a cultural expression that does not happen by chance but is created informally or by design.

Thinkers about heritage and cultural landscapes are increasingly recognising the need for cultural and natural elements to be considered together. Both elements are essential parts of the construction of cultural landscape. They are also key components of a sense of place.

As argued in the next paragraph, connection with governance arrangements cultural landscapes can be constituted as action arenas for regional development. Landscapes need not be monumental or rare in order to mediate between the natural and the social. Common historical roots, significant landscape features, local gastronomy, cultural traditions as well as innovative projects are possible initial points for identity-based region-building processes.

Ecomuseum: history and evolution. Ecomuseum is a compound world of ecology and museum. This includes heritage and human activities, including nature, ecology and industry, it is designated as the range of museum, where the whole territory is organically constituted, and the residents voluntarily participate in the operation. It is a cultural institution that ensures on a permanent basis, for a specific territory and with the participation of the population, the functions of research, conservation, development of a set of natural and cultural assets, which are representative of an environment and the ways of life that have taken place there.

The Ecomuseum experience took place in France in the early ' 70 s thanks to the intuition of the museologist Georges Henri Rivière [5], who describes them as:

"It is an expression of man and nature. It situates man in his natural environment.

It is an expression of time, when the explanations it offers reach back before the appearance of man, ascend the course of the prehistoric and historical times in which he lived and arrive finally at man's present. It is an interpretation of space-of special places in which to stop or stroll.

It is a laboratory, in so far as it contributes to the study of the past and present of the population concerned and of its environment and promotes the training of specialists in these fields, in co-operation with outside research bodies.

It is a conservation centre, in so far as it helps to preserve and develop the natural and cultural heritage of the population.

It is a school, in so far as it involves the population in its work of study and protection and encourages it to have a clearer grasp of its own future.

This laboratory, conservation centre and school are based on common principles. The culture in the name of which they exist is to be understood in its broadest sense, and they are concerned to foster awareness of its dignity and artistic manifestations, from whatever stratum of the population they derive.

Its diversity is limitless, so greatly do its elements vary from one specimen to another. This triad, then, is not self-enclosed: it receives and it gives."

They have spread first to France (where there is a federation of eco-museums) and other French-speaking countries such as Canada, then tested in several European countries and in different territorial situations, such as surrounding areas including parks or natural areas, abandoned industrial areas or valleys remained marginalized from the development of mass tourism. Nowadays they are appearing on the Italian scene as one of the most innovative in the difficult conjugation of conservation and development.

An ecomuseum of the cultural landscape focuses on the whole territory as a popular museum, where once again make readable and valuable - first to its population - the identity and the diversity of 
its landscape, the material and immaterial culture rooted over the centuries, the characteristics and values that can guide more coherent development policies.

The ecomuseum seeks to preserve the heritage land where the heritage has been built and where it is modified daily (obviously trying to control these processing activities). In this task it cannot involve the people, without whose contribution an ecomuseum would be totally ineffective.

The research activities carried out are not targeted to a general updating of knowledge on heritage or to deal with new demands of an audience of visitors, but are aimed at specific actions that consciously make the ecomuseum enhancing a particular territory's aspect and to promote its development. Clearly these actions would be totally ineffective if they were not decided within a local shared framework (people and administrations) and they need to be carried out in situ.

As previously said, an ecomuseum like any museum institution must perform certain functions (collections care, research, cultural communication) starting from exhibiting its own a collection. But in this case the collection is the whole territory and the culture of its inhabitants [6]. Buildings and infrastructure related to traditional activities, which over time have changed the landscape, will therefore be its main findings, along with craft items of daily use, useful to describe the lifestyles of the population, or as well as intangible items such anecdotes, songs, gastronomy, dialects and so on.

Often the desire of some residents to prevent the disappearance of their cultural heritage, together with the availability of a property of some historical value, push the constitution of an ecomuseum. However, often this is not the best nor feasible way.

It is very challenging to perform the functions mentioned above, which are essential for the startup of an eco-museum, it, especially in relation to the particular type of assets to be promoted. The mere preservation of traditional artifacts can be useful even in the absence of research and communication with the public. In the case of territorial heritage instead, it is not possible to preserve at the same time if you do not make the local community aware of the value of the territory which they lives.

Italian and Regional Normative system. In October 2009, with a specific bill presentation to the Chamber of Deputies and the will officially expressed by the Ministry of Tourism to set up a Committee for the development of ecomuseums, Italy has opened a phase of internal debate on the relationship between ecomuseum and tourism promotion. Certainly not a mass tourism but a sustainable one, respectful of cultural heritage that the ecomuseums can adequately support thanks to their participatory nature and the widespread attention to the exploitation of landscape and local identity.

In this perspective, the induced loss is not the only added value of integration between tourism and eco-museums, but also building cultural and socio-economic relationships among external to the local system subjects, which eliminates the implicit risk of self-referentiality and closing.

The design of ecomuseums really seems to represent a turning point in the collective representation of the everyday landscape and local realities, and therefore it deserves a detailed development.

Initiatives to develop the evolutionary model of ecomuseum, incentives for cooperation between different ecomuseums, exchanges of experiences and personnel, are all factors that can contribute to increase the ability to converse with different cultures.

The ecomuseum planning is a strategic tool to revitalize identity values that find expression in the landscape as a product of interaction evolution between natural and cultural factors, according to the European Landscape Convention [7]. The Convention underlines the importance of landscape as an identifier and a link between local communities with their points of reference.

The constant growth of ecomuseums in recent years has encouraged the development of new tools and methods for deepening and enhancing landscape in relation to local self-sustaining development, endorsed by the Calabria Region, with the Regional Law establishing the Ecomuseums in Calabria [8].

The proposed ecomuseum formula intends to contribute to the statement of new landscape meanings and values, contributing to the diffusion of people roots to their own territory and communicating the system of natural and cultural information herein contained. 


\section{A Pilot Project for the Enhancement of Integrated Aspromonte National Park}

The aim of the project presented in this paper, is to foster the development of the area of Aspromonte National Park, by definition and construction of the "Network of Ecomuseums of Aspromonte National Park", primarily aimed at the recognition of the identifying characteristics of Aspromonte as an inseparable reality and to the identification of "rurality" as an important tourist attraction and endogenous development.

The objectives, therefore, can be summarized as follows:

- Promote the local culture and society, through participative dynamics;

- Strengthen the governance system related to the development processes management of Aspromonte National Park local resources;

- Identify and build "sense of place" around the resources that qualify the Aspromonte area, investigating its significant value.

- Develop local competitiveness and ability to attract investment, with the implementation of territorial marketing policies targeted to the needs and expectations of local and external economic operators, while firmly remaining in logic of protection and preservation of environmental and cultural features of the National Park.

Given the feature of the concerned heritage and the expansion of the chosen area, the definition of the objectives takes into account:

- Systemic externalities arising from new cultural relations established among the developing cultural sites and external cultural assets of Aspromonte;

- Consumption externalities, resulting from expected increases in terms of Aspromonte cultural heritage economic demand;

- Scale and/or Scope Economies, derived from potential economic benefits arising from the integration of management functions or activities for various reasons related to the preservation and promotion of Aspromonte cultural heritage.

The proposed research follows the definition of the regional areas as part of the cooperation experiences gained from recent legislation on the identification of Local Tourist District investigating the identification of the area among the Tyrrhenian Sea, Ionian Sea, and the Strait of Messina. It experiments joint cultural activities, suitable for the creation of international ecomuseum tours. According to the network, this project aims to drive complex and environment friendly tourist routes inside the park, to enhance the cultural heritage distributed in time and space and therefore bearer of sustainable development. The identification of pilot areas for the detection of Aspromonte Ecomuseums Network comes from a deep spatial holistic analysis on a regional scale, mainly based on the persistence of Aspromonte distinctiveness, albeit in its many peculiarities and vocations [9].

\section{Conclusions and possible developments}

The creation of ecomuseums is aimed at recovering the productivity and enhancing the cultural, economic and social resources through the reconversion and the promotion of environmentally-friendly local identity.

The general objective of the project is to encourage the development of the Aspromonte National Park by definition and construction of the "Network of Ecomuseums of Aspromonte National Park", aimed to the recognition of the identifying characteristics of the Aspromonte as an whole set of heritage resources and to the identification of "rurality" as an important and potential tourist attraction and endogenous development element.

According to the purpose and strategic goals declared, the "Network of Ecomuseums of Aspromonte National Park", is therefore proposing as a strategic program of territorial integration, since the identification of local actors, cultural resources and the production chains involved, as well as the degree of expected: 
1. Political and programmatic integration, aimed at the realization of the upstream intervention strategies that will help to realize a unified and shared decision-making procedure among stakeholders;

2. Integration of the supply system, aimed at sharing operational practices and supply of goods and activities;

3. Management integration, aimed at sharing and set up system of production processes and, thus, the "business" functions that make up the individual supply chains;

4. Integration of communication and promotion techniques within the network and then the whole park area.

The expected results through the model testing and implementation are:

- Cultural and Educational impact: the enhancement of local cultural resources fosters identity awareness, the spread of the rich local culture, the strengthening of the spirit of belonging and sense of place.

- Employment Implications: the enhancement of cultural heritage has many synergies with agriculture/crafts, commerce and tourism.

- Effect on tourism flows: the aim is to increase the total number of tourists by improving usability, management and visibility of resources, with positive effects for the entire industrial sector;

- Environmental Impact: the activation of an eco-museum dedicated to the landscape discovery, aims to promote integration, harmonization processes and to rebalance artificial and natural resources, ensuring the proper implementation of the principles of environmental sustainability.

\section{References}

[1] F. Calabrò, L. Della Spina: The cultural and environmental resources for sustainable development of rural areas in economically disadvantaged contexts. Economic-appraisals issues of a model of management for the valorisation of public assets, in: 3rd International Conference on Energy, Environment and Sustainable Development (ICEESD 2013). Advanced Materials Research Vols. 869-870 (2014) pp 43-48 (C) (2014) Trans Tech Publications, Switzerland doi:10.4028/www.scientific.net/AMR.869-870.43, (2014)

[2] ICOMOS USA Natchitoches Declaration on Heritage Landscapes, Information on http://www.icomos.org/usicomos/, United States Committee, International Council on Monuments and Sites (2004)

[3] O. Young: The Institutional Dimensions of Environmental Change - Fit, Interplay, and Scale, edited by MIT-Press, Cambridge (MA), London (2002)

[4] A. Röhring: The common good aspects and institutional problems of cultural landscape - an analysis of regional development issues using institutional theory, presented at Building the European Commons: From Open Fields to Open Sources, edited by IASCP, Brescia (2006)

[5] G. H. Rivière, in: Museum International. The ecomuseum - an evolutive definition, 37 (1985), pp. 182-183

[6] P. Davis: Ecomuseums: a sense of place, Leicester University Press, (1999)

[7] Council of Europe: European Landscape Convention, Brussels, (2000)

[8] Calabria Regional Law, 4 December 2012 n. 62, published in the BUR n. 22 - 1 December 2012, extraordinary supplement n. 4 - 11 December 2012.

[9] G. Cassalia, M. Malaspina, C. Ventura: Clearing Memories from Bushes: Rediscovery Identity of Places Along the Path of Zanotti Bianco in Aspromonte, in Utopias and dystopias in landscape and cultural mosaic. Visions Values Vulnerability - Conference proceedings. XVII Convegno IPSAPA/ISPALEM, Udine, (2013), pp. 255-260. 